\title{
Microstructure and Tensile Behavior of Ni-Base Metal- Intermetallic Laminate Composites Prepared by Plasma Activated Sintering
}

\author{
Guo Yajie ${ }^{1}, \quad$ Shi Zhongqi ${ }^{2}, \quad$ Xu Yiku ${ }^{1}, \quad$ Qiao Guanjun ${ }^{2}, \quad$ Wang Jian $^{3}$ \\ ${ }^{1}$ Chang'an University, Xi'an 710064, China; ${ }^{2}$ State Key Laboratory for Mechanical Behavior of Materials, Xi'an Jiaotong University, Xi'an \\ 710049, China: ${ }^{3}$ State Key Laboratory for Porous Metal Materials, Northwest Institute for Nonferrous Metal Research, Xi'an 710016, China
}

\begin{abstract}
Ni-base metal-intermetallic laminate (MIL) composites were obtained from in-situ combustion reaction between the Ni and $\mathrm{Al}$ foils by a plasma activated sintering (PAS). Microstructural observation reveals that the laminates consist of alternate residual Ni layers and reacted layers which can be further divided into multiple layers of Ni-aluminides. The compositional gradient series of these intermetallic phases change in a stepwise fashion from Al-rich phases to Ni-rich phases with the increasing of the treatment temperature. Accordingly, the tensile strength of the composite increases steadily with the increase of temperature. The composites fabricated at $1473 \mathrm{~K}$ have the highest tensile strength and elongation. The fractographies of the tensile samples indicate that the failure of the composites treated at lower temperatures (1073 K and $1173 \mathrm{~K})$ result from the interaction between the transversal cracks in the intermetallic layers and the shear bands in the Ni layers. When the treatment temperature increases, a transition from multiple cracking to a single cracking of the intermetallic layers can be observed.
\end{abstract}

Key words: composites; intermetallics; self-propagating synthesis; tensile behavior

An economic route for the production of bulk materials is of a considerably scientific and industrial interest. Combustion synthesis (CS), also termed as reaction synthesis (RS), is believed to be a candidate technique to form ceramics, intermetallics and their composites at operating temperatures much lower than their melting points in very short processing time $^{[1]}$. The energy saving and economic benefits of this technique has been widely acknowledged. Recently, the CS technique has been adopted to produce fully dense metal-intermetallic laminate (MIL) composites using metal foils as the starting materials ${ }^{[2]}$. And the novelty of this process lies in that the composition, physical and mechanical properties of the MIL composites can be readily tailored by simply varying the element foil compositions, thicknesses and layering sequence. Moreover, many advantages with respect to the process, such as cost-savings, ease in achieving full-density and near-net-shape products through pre-deformation prior to reaction sintering, and in situ well-bonding between the metal and the intermetallics, were proclaimed ${ }^{[3]}$.

Researchers at the United States Bureau of Mines pioneered in fabricating the $(\mathrm{Fe}, \mathrm{Ni}, \mathrm{Ti})-\mathrm{Al} \mathrm{MIL}$ composites through this process by a vacuum hot-press furnace ${ }^{[3,4]}$. Hereafter, Harach and Vecchio ${ }^{[5]}$ modified the process to produce $\mathrm{Al}_{3} \mathrm{Ti} / \mathrm{Al} \mathrm{MIL}$ composites in an open air, which minimized the cost of equipments and provided the greatest flexibility in processing apparatus and composite shapes. However, up to now, this modified process has been limited to the Ti/Al system. Subsequently, further investigations concerning $\mathrm{Ni}-\mathrm{Al}^{[6-8]}$, $\mathrm{Cu}-\mathrm{Ti}^{[9,10]}$ and $\mathrm{Ti} / \mathrm{Al}^{[11]}$ MIL composites were carried on. It is noted that these processes are generally accomplished in several hours. To further improve the efficiency of these processes, Mizuuchi et $a l^{[12]}$ reported a pulsed-current hot

Received date: April 17, 2013

Foundation item: National Natural Science Foundation of China (50571078); The Foundation of State Key Laboratory for Mechanical Behavior of Materials (20121203); Special Fund for Basic Scientific Research of Central Colleges, Chang'an University (CHD2011JC139)

Corresponding author: Guo Yajie, Ph. D., Lecturer, School of Materials Science and Engineering, Chang'an University, Xi'an 710064, P. R. China, Tel: 0086-29-82337340, E-mail: yjguo@chd.edu.cn

Copyright $($ C 2014, Northwest Institute for Nonferrous Metal Research. Published by Elsevier BV. All rights reserved. 
pressing (PCHP), where the pulsed-current sintering (PCS), combustion synthesis and vacuum hot pressing were combined to facilitate the process could be accomplished in 10 min. This modified process shows a great potential in rapid fabricating of the MIL composites, and more details concerning the process need to be clarified.

In the present work, Ni-Al MIL composites were produced by plasma activated sintering (PAS) from $\mathrm{Ni}$ and $\mathrm{Al}$ elemental foils. The PAS is an electric current assisted sintering equipment which is similar to the $\mathrm{PCS}^{[13]}$. The microstructure and tensile properties of the composites were investigated. And the failure mechanism of the composites under tensile loading was discussed based on the observation of the fractured samples.

\section{Experiment}

Commercially available foils of $\mathrm{Ni}$ (purity: 99.9\%, thickness: $50 \mu \mathrm{m}$ and $100 \mu \mathrm{m}$ ) and $\mathrm{Al}$ (purity: 99.7\%, thickness: $100 \mu \mathrm{m}$ ) were cut into $\Phi 40 \mathrm{~mm}$ disks and cleaned in the ultrasonic bath of acetone for $10 \mathrm{~min}$. Any contamination on the surface of the foils was subsequently cleaned using degreased cotton swabs. After cleaning, $15 \mathrm{Ni}$ foils and $14 \mathrm{Al}$ foils were alternatively stacked into a cylindrical graphite die and processed by PAS (Ed-PASIII, Elenix Ltd, Japan). The plies were initially heated to $973 \mathrm{~K}$ at an average heat rate of $5 \mathrm{~K} / \mathrm{s}$ under a pressure of $2.7 \mathrm{MPa}$ and were held for $90 \mathrm{~s}$ to ensure that the reaction between the $\mathrm{Ni}$ and $\mathrm{Al}$ foils had gone to completion prior to the following heating. When the plies were heated to the given temperatures $(1073 \mathrm{~K}, 1173 \mathrm{~K}, 1273 \mathrm{~K}$ or $1473 \mathrm{~K})$, the uniaxial loading was increased from 2.7 $\mathrm{MPa}$ to $32 \mathrm{MPa}$ and held for $600 \mathrm{~s}$ to ensure the high density of the laminates. After holding, the plies were furnace-cooled to room temperature and the pressure was released at $873 \mathrm{~K}$. To minimize the heat loss during the combustion reaction, the internal wall of the die was coated with a thin layer of boron nitride and both ends of the stacked plies were thermally insulated by zirconia felt.

The characterization of the microstructure was performed via scanning electron microscope (SEM) with energy dispersive X-ray spectrometer (EDS), X-ray diffractometer (XRD) and transmission electron microscope (TEM). For TEM, the cross-sectional specimen was cut using a spark cutter, ground to $40 \mu \mathrm{m}$, and ion milled supporting by a double folding aperture grids. The prepared sample was analyzed in a TEM (JEOL-2000EX, $200 \mathrm{keV}$ ).

Flat dog-bone shape tensile specimens were electro-discharge machined from the as-processed MIL composites to determine the mechanical properties ${ }^{[14]}$. The tensile tests were performed at room temperature using an Instron screw machine with a strain extensometer at the strain rate of $5 \times 10^{-3} \mathrm{~s}^{-1}$, and the tensile direction was parallel to the laminated layers. Before tension, the lateral walls of the specimens were carefully polished initially with grade $800 \#$ abrasive papers and finally using $0.05 \mu \mathrm{m} \mathrm{Al}_{2} \mathrm{O}_{3}$ powder.

\section{Results and Discussion}

\subsection{Microstructural characterization and phase identifi- cation}

Fig.1 shows a typical microstructure of the laminates prepared by PAS. It is apparent that the reaction between the $\mathrm{Ni}$ and $\mathrm{Al}$ foils results in a transition structure with two distinct layers (Fig.1a). EDS analysis elucidates that the bright layers are the residual $\mathrm{Ni}$. As pointed by Kim et al ${ }^{[8]}$, the CS reaction was not self-sustaining when the combined thickness of $\mathrm{Ni}$ and $\mathrm{Al}$ foils exceeded $20 \mu \mathrm{m}$ due to the heat dissipation through the metal layers. As a result, the Ni layers are residual As can be seen from Fig.1b, the grain size of the $\mathrm{Ni}$ is large due to that the exposing to high temperatures enables the recrystallization and the grain growth of the $\mathrm{Ni}$ layers. Extremely, a sole grain extends to cover the Ni layers in the direction of thickness. The initial $\mathrm{Al}$ foils are completely consumed and transformed into dark layers. It is noted that the thickness of the reacted layers is far from that calculated according to the initial composition ratio of $\mathrm{Ni}$ to $\mathrm{Al}$ due to that a part of $\mathrm{Al}$ is squeezed out under the applied loading. At higher magnification, some pores along the central line of the reacted layers can be observed (Fig.1b). And the porosity decreases with the increase of temperatures. It indicates that to obtain good mechanical properties, higher load and temperatures are required to ensure elimination of the residual pores.

Fig.2 presents back scattered electron (BSC) images of the reacted layers in the laminates prepared at various temperatures. It can be seen that all the reacted layers are composed of multiple individual layers. Concretely, the reacted layers of the laminates processed at $1073 \mathrm{~K}$ have a symmetric structure of $\mathrm{Ni}_{3} \mathrm{Al} / \mathrm{Ni}$-rich phase/NiAl/ $\mathrm{Ni}_{2} \mathrm{Al}_{3} / \mathrm{NiAl} / \mathrm{Ni}$-rich phase $/ \mathrm{Ni}_{3} \mathrm{Al}$ (Fig.2a). There is apparent backscattered electron contrast between the $\mathrm{NiAl}$ and Ni-rich phase $(67 \mathrm{at} \% \mathrm{Ni})$. It is noted that it is difficult to identify that the type of the Ni-rich phase in view of the $\mathrm{NiAl}$ phase is stable in a wide range of $\mathrm{Ni}$ contents (42 at\% 67 at\%). Using the TEM analysis, we found that the Ni-rich phase is essentially a supersaturated solid solution with precipitation (Fig.3). The $\mathrm{NiAl}$ and $\mathrm{Ni}_{3} \mathrm{Al}$ phase with superlattice structures can also be identified from Fig.3. When the treatment temperatures are increased to $1173 \mathrm{~K}$ and

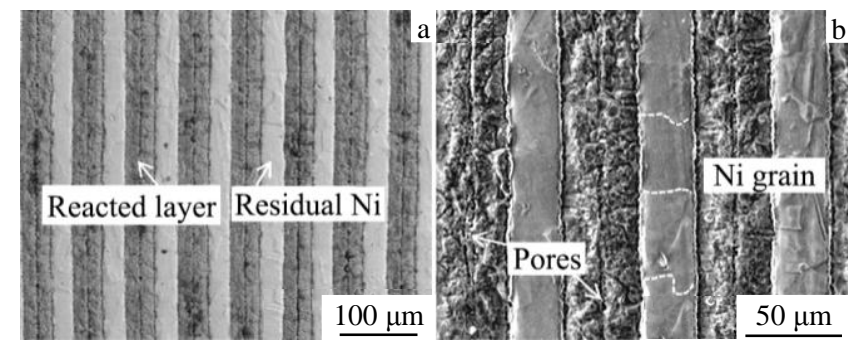

Fig.1 Typical SEM images of the laminates prepared by PAS (1073 K, $32 \mathrm{MPa}, 600 \mathrm{~s}$ ) 


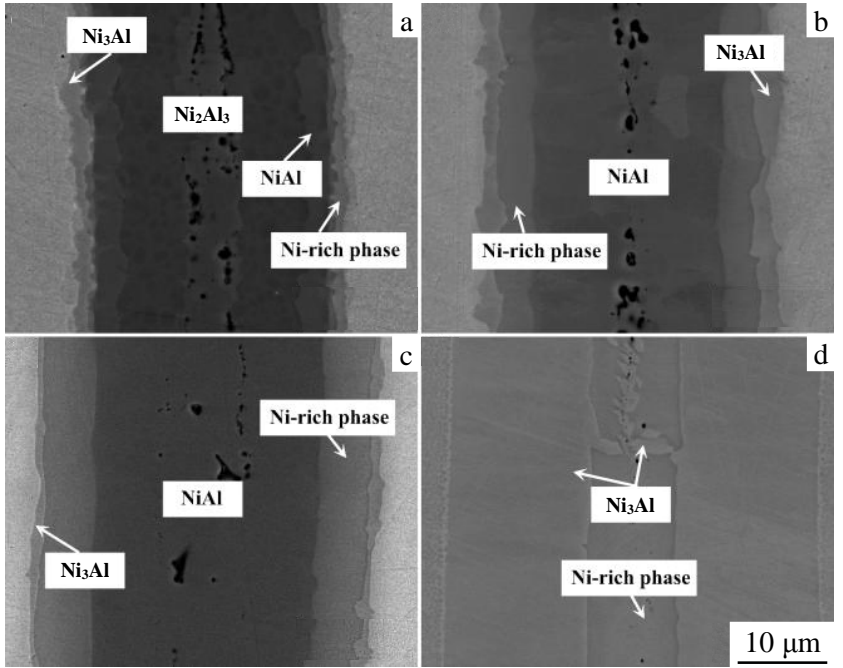

Fig.2 Effect of the treated temperatures on the microstructure evolution of the laminates prepared by PAS: (a) $1073 \mathrm{~K}$, (b) $1173 \mathrm{~K}$, (c) $1273 \mathrm{~K}$, and (d) $1473 \mathrm{~K}$

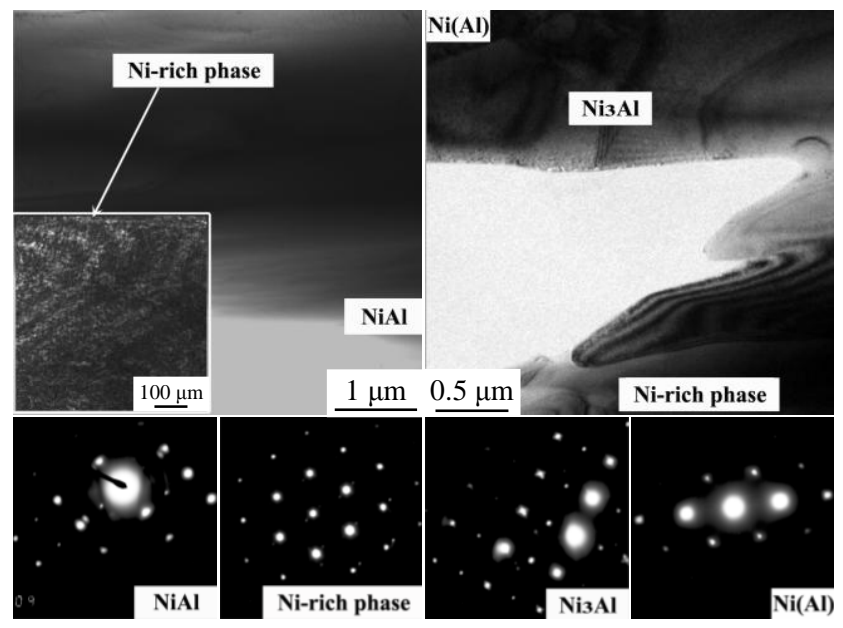

Fig.3 TEM images of the interface between the Ni layer and the intermetallic layer after holding at $1273 \mathrm{~K}$ for $600 \mathrm{~s}$ with the corresponding selected area electron diffraction patterns

$1273 \mathrm{~K}$, the primarily intermetallic layer transforms from $\mathrm{Ni}_{2} \mathrm{Al}_{3}$ into $\mathrm{NiAl}$ phase. The transformation of the intermetallic phases in a stepwise fashion from Al-rich phases to Ni-rich phases may be attributed to the enhanced interdiffusion between $\mathrm{Ni}$ and $\mathrm{Al}$ at higher temperatures. This trend can be further verified by the XRD analysis, as can be seen from Fig.4. Compared with those treated at lower temperatures, the composites fabricated at $1473 \mathrm{~K}$ exhibit a cellular structure where the Ni-rich phase is divided and enclosed by the $\mathrm{Ni}_{3} \mathrm{Al}$ phase (Fig.2d). The same structure was also obtained by Mizuuchi et $a l^{[12]}$ who suggested that such cellular $\mathrm{Ni}_{3} \mathrm{Al}$ could be capable of prohibiting the crack propagation during tensile tests.

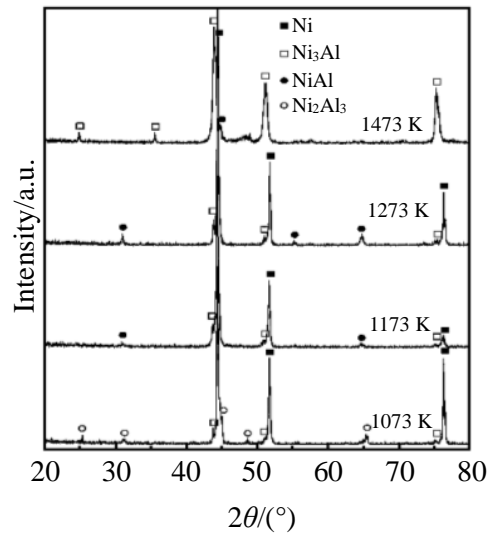

Fig.4 XRD patterns of laminates produced at different temperatures

\subsection{Tensile stress-strain curve}

Uniaxial tensile tests along the direction parallel to the layers were carried out for the composites, and the typical examples of the stress-strain curves tested at $293 \mathrm{~K}$ are shown in Fig.5. It can be seen that the samples treated at $1073 \mathrm{~K}$, $1273 \mathrm{~K}$ and $1473 \mathrm{~K}$ exhibit a plastic deformation before the fracture. And the tensile strength of the composites increases gradually with the increasing of the treated temperatures. Both the tensile strength and the elongation of the samples treated at $1473 \mathrm{~K}$ are enhanced. This enhancement may be related to the solid solution hardening of the Ni matrix with the increase of $\mathrm{Al}$ content in Ni matrix and/or the reduction of the residual pores in the intermetallic layers. It is difficult to predict the tensile behavior of these laminates through the rule of mixture (ROM) because the mechanical properties of the Ni-aluminides prepared by $\mathrm{CS}$ are highly sensitive to the processing condition, the microstructure and the composition, as pointed by Kim et $a l^{[7]}$. The elongations of the samples decrease firstly and then increase, as can be seen in Fig.5. The composites treated at the intermediate temperature, $1173 \mathrm{~K}$, show a sharp decrease of the elongation compared to those of the samples treated at $1073 \mathrm{~K}, 1273 \mathrm{~K}$ and $1473 \mathrm{~K}$.

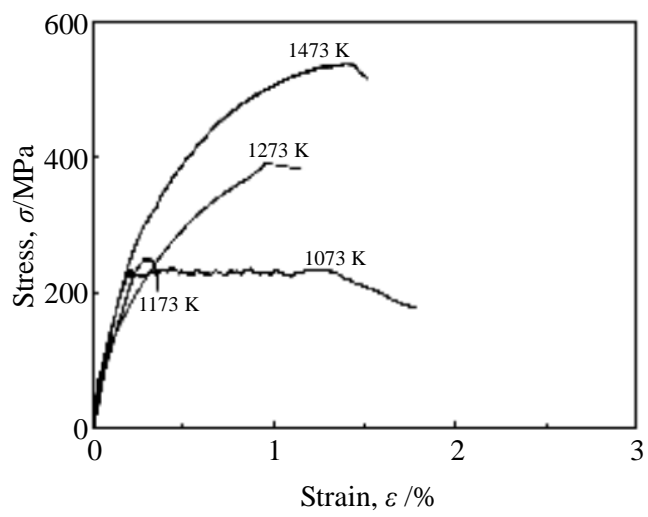

Fig.5 Engineering stress-engineering strain curves of laminates treated at different temperatures 
It is noted that the curve of the samples treated at $1073 \mathrm{~K}$ shows a distinct difference to those of the three others. There is a platform with tiny serration in the curve, which corresponds to the fluctuation of the loading. Alman et $a l^{[3]}$ suggested that the load dropping could be attributed to the fracture of the intermetallic layers. The fractured layers would be bridged by the Ni layers and thus lead to work hardening of the Ni layers, which would make up the load drop from the fracture of the intermetallic layers and enable the deformation continued for a while around this stress level.

\subsection{Fracture mechanism}

The fracture surface and the lateral surface (along the longitudinal direction and perpendicular to the layers) of such laminates were investigated to reveal the fracture process. From the side view, the fracture surface of the samples treated at $1073 \mathrm{~K}$ is tortuous (Fig.6a). Several lateral cracks, parallel to the stress direction, lead to the large-scale delamination along the central line of the reacted layers. Rawers et $a l^{[4]}$ suggested that these lateral cracks were initiated by the difference in the stress levels between the metal layers near the surface and the inner metal layers highly constrained. However, we found that the lateral cracks, which are not limited to the near surface layers, are prone to initiate at the place where the adjacent $\mathrm{Ni}$ layers involve severe plastic deformation. It is indicated that these lateral cracks may be ignited by the transverse stress introduced by the asymmetric local plastic deformation of the neighboring Ni layers. Moreover, the numerous pores in the center line of the intermetallic layers may accelerate the delamination process. Another important feature of the fractured samples treated at $1073 \mathrm{~K}$ is the linkage of numerous shear bands in the Ni layers and the transverse cracks in the intermetallic layers. Two kinds of transverse cracks can be observed. One is straight with larger crack opening displacement (COD), and the another is tilted towards the nearest shear band with lower COD. Then, it is conceivable that the sample treated at $1073 \mathrm{~K}$ fractured in the following way: the onset of the failure begins with the initiation of a few transverse cracks in the intermetallic layers at the place with local defects. Considering the regions between the opposite cracks, i.e., a small spacing with large grain of $\mathrm{Ni}$ constrained by hardly deformed intermetallic layers, it is reasonable to postulate that the rotation of the $\mathrm{Ni}$ crystallites must be restricted and as an alternative of the transcrystalline slip of $\mathrm{Ni}$, which is limited to the shear bands, produced. Conversely, when the shear bands propagate, the accompanying stress concentration is strong enough to initiate new cracks in the adjacent intermetallic layers. The multiplication of the cracks in the intermetallic layers and the shear bands in the Ni layers interacts until both the cracks and shear bands are saturated. One or more Ni layers lose their capability of further plastic deformation and the final failure of the laminates is inevitable. The fracture surface of the samples treated at 1073 K (Fig.6b)

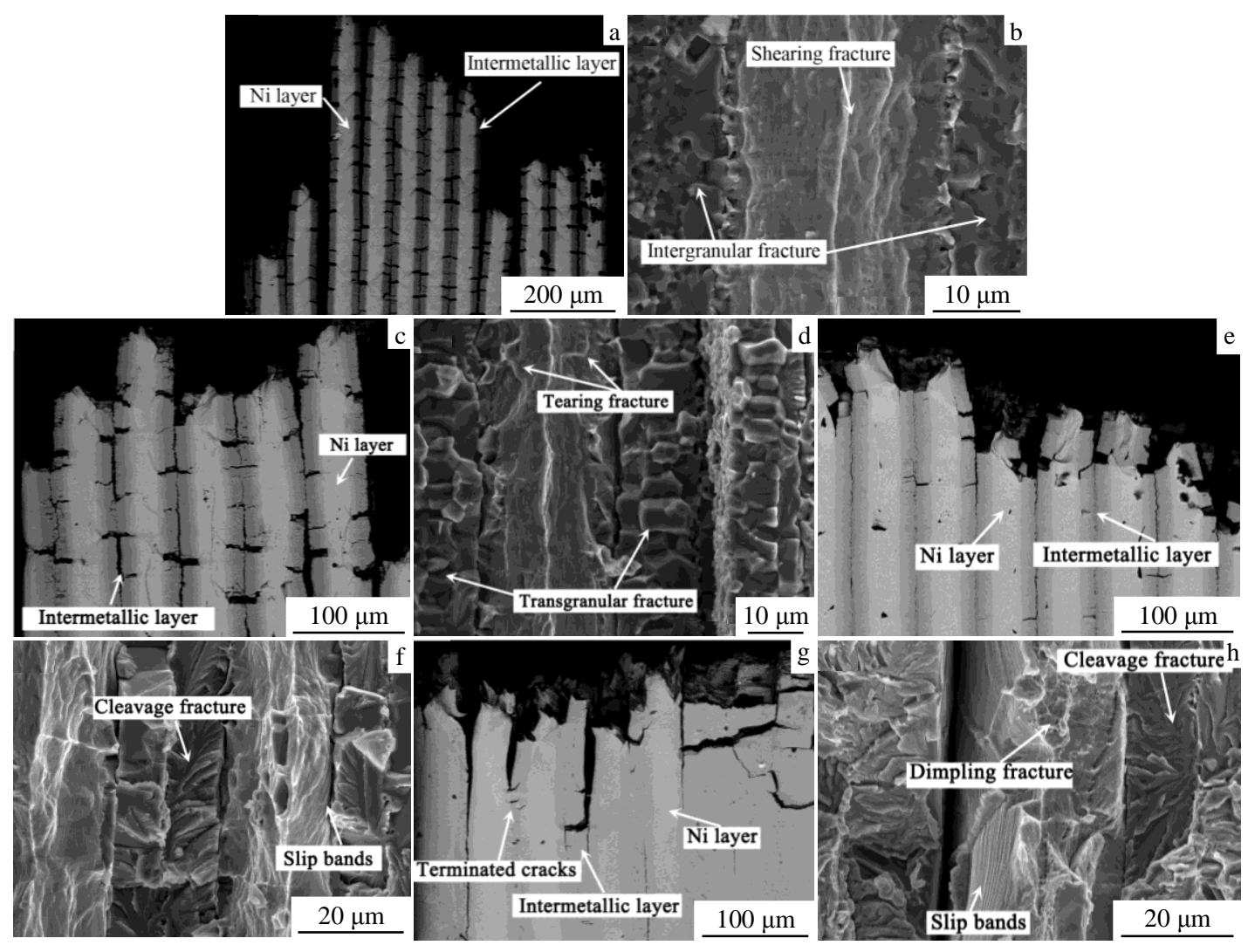

Fig.6 SEM images of fracture surfaces and lateral surface after tensile testing of the laminates prepared at $1073 \mathrm{~K}(\mathrm{a}, \mathrm{b})$, $1173 \mathrm{~K}(\mathrm{c}, \mathrm{d}), 1273 \mathrm{~K}(\mathrm{e}, \mathrm{f}), 1473 \mathrm{~K}(\mathrm{~g}, \mathrm{~h})$ for $600 \mathrm{~s}$ 
shows slip step (commonly resulted from the shearing fracture) in the ductile Ni layers and transgranular cleavage facets in the reacted layers.

Compared to those treated at $1073 \mathrm{~K}$, the samples treated at $1173 \mathrm{~K}$ shows apparent decrease with respect to the transverse cracks in the intermetallic layers and shear bands in the $\mathrm{Ni}$ layers as well as the delamination (Fig.6c). All of them are limited to the region near the fracture surface, leaving most parts of the samples intact. The fracture surface of Ni layers shows shearing and tearing characters. And the intermetallic layers show dominantly an intergranular fracture mode. Then it can be postulated that the cracks initiated in the intermetallic layers would rapidly propagate and consequently the regions of the Ni layers approach to the crack tips undergoing high local loading rates, which eventually leads to the enhanced tensile strength and lowered elongation in comparison with those of the samples treated at $1073 \mathrm{~K}$. Correspondingly, the samples treated at $1173 \mathrm{~K}$ fail quickly after yielding, as is shown in Fig.5.

Instead of the multiple cracking and the delamination of the intermetallic layers, the sample treated at $1273 \mathrm{~K}$ fractures with a main crack propagating along the direction of 45 degree angle to the applied loading (Fig.6e). It is indicated that the Ni layers and the intermetallic layers maintain an uniform strain pattern at the early stage of the tensile process to a very high level of stress before the initiation of cracks in the intermetallic layers due to local defects. However, the $\mathrm{Ni}$ layers are highly constrained by the long fragments of the intermetallic layers so that the dislocation glide is mainly concentrated in the narrow bands with a preferred orientation to the maximum shear stress. Subsequently, the concentrated slip bands would initiate a new crack in the adjacent intermetallic layers. Then, the failure of the composites relied on a main crack progresses along the direction of 45 degree angle to the applied loading. Accordingly, extensive slip bands having a 45 degree angle with the interface can also be viewed on the fracture surface (Fig.6f). And the fracture surface of the intermetallic layers consists of transgranular cleavage facets.

From the side view, the fracture surface of the sample treated at $1473 \mathrm{~K}$ is flat, i.e., almost in a line along the transverse direction (Fig.6g). Delamination between the interface of Ni-rich phase and $\mathrm{Ni}_{3} \mathrm{Al}$ is occasionally observed. There are no shear bands developed within the Ni layers. It may be related to the higher level of solution strengthening in the $\mathrm{Ni}$ layers treated at $1473 \mathrm{~K}$. Moreover, rare transverse cracks can be found in the intermetallic layers. It is indicated that the intermetallic layers can cooperatively deformed with the Ni layers in the tensile process instead of cracking into fragments. As pointed out by Wang et al ${ }^{[15]}$, the $\mathrm{Ni}_{3} \mathrm{Al}$ layers in the multilayer composites produced through in situ reaction synthesis have a similar and low energy, a coherent interface with the Ni layers. The dislocations in the Ni layers can easily glide through the coherent interfaces between the $\mathrm{Ni}_{3} \mathrm{Al}$ and the Ni layers along some certain planes, and do not pile up at the interfaces. This can be partly verified by the observation of some slip-bands at the delaminated $\mathrm{Ni}_{3} \mathrm{Al} / \mathrm{Ni}$ interfaces (Fig.6h). Correspondingly, the laminates show higher elongation than that of the others treated at lower temperatures. The fracture surface of the Ni layers shows void coursing and the intermetallic layers shows typical cleavage patterns.

\section{Conclusions}

1) The laminated metal-intermetallic composites where the intermetallic layers are composed of multiple individual layers with compositional grade can be rapidly fabricated by PAS from the $\mathrm{Ni}$ and $\mathrm{Al}$ foils. The dominant phase of the intermetallic layers will convert from $\mathrm{Ni}_{2} \mathrm{Al}_{3}$ to $\mathrm{Ni}_{3} \mathrm{Al}$ with the increasing of the treatment temperature.

2) With the increase of temperature, the tensile strength of the laminates increases gradually. Both the tensile strength and the elongation of the laminates treated at $1473 \mathrm{~K}$ are enhanced.

3) The failure of the laminates is initiated by the cracking of the intermetallic layers. However, the multiplication mechanism of the cracks depends upon the Ni layers. When the composites are treated at lower temperature $(1073 \mathrm{~K}$ and $1173 \mathrm{~K}$ ), the ductile Ni layer shear deformation allowed can initiate new cracks in adjacent intermetallic layers. And the final fracture occurs through the linkage of multiple cracks and shear bands. However, in the case of higher treatment temperature $(1473 \mathrm{~K})$, the shear deformation of the Ni layers is limited. The failure of the ductile layer proceeded by the propagation of a single (or a few) dominant $\operatorname{crack}(\mathrm{s}$ ) will be through the composite.

\section{References}

1 Morsi K. Materials Science and Engineering A[J], 2001, 299(1-2): 1

2 Rawers J C, Hansen J S, Alman D E et al. Journal of Materials Science Letters[J], 1994, 13(18): 1357

3 Alman D E, Dogn C P, Hawk J A et al. Materials Science and Engineering A[J], 1995, 192-193: 624

4 Rawers J, Perry K. Journal of Materials Science[J], 1996, 31(13): 3501

5 Harach D J, Vecchio K S. Metallurgical and Materials Transactions A[J], 2001, 32(6): 1493

6 Zhu P, Li J C M, Liu C T. Materials Science and Engineering $A[\mathrm{~J}], 2003,357(1-2): 248$

7 Kim H Y, Chung D S, Enoki M et al. Journal of Materials Research[J], 2006, 21(5): 1141

8 Kim H Y, Chung D S, Hong S H. Scripta Materialia[J], 2006, 54(9): 1715

9 Konieczny M, Dziadon A. Materials Science and Engineering $A[\mathrm{~J}], 2007,460-461: 238$ 
10 Konieczny M. Materials Characterization[J], 2012, 70: 117

11 Peng L M, Wang J H, Li H et al. Scripta Materialia[J], 2005, 52(3): 243

12 Mizuuchi K, Inoue K, Sugioka M et al. Materials Science and Engineering $A[\mathrm{~J}], 2006,428(1-2): 169$

13 Munir Z A, Quach D V, Ohyanagi M. Journal of the American
Ceramic Society [J], 2011, 94(1): 1

14 Guo Y J, Qiao G J, Jian W Z et al. Materials Science and Engineering $A[\mathrm{~J}], 2010,527(20): 5234$

15 Wang H, Han J, Du S et al. Metallurgical and Materials Transactions A[J], 2007, 38(2): 409

\title{
等离子活化烧结法制备 $\mathrm{Ni}$ 基金属/金属间化合物叠层 复合材料微观组织与拉伸行为
}

\author{
郭亚杰 ${ }^{1}$, 史忠旗 ${ }^{2}$, 徐义库 ${ }^{1}$, 乔冠军 ${ }^{2}$, 王 建 $^{3}$ \\ (1. 长安大学, 陕西 西安 710064) \\ (2. 西安交通大学 金属材料强度国家重点实验室, 陕西 西安 710049)
}

(3. 西北有色金属研究院 金属多孔材料国家重点实验室, 陕西 西安 710016)

\begin{abstract}
摘 要: 采用等离子活化烧结法, 通过 $\mathrm{Ni}$ 䇴和 $\mathrm{Al}$ 箔的原位燃烧反应制备了镍基金属/金属间化合物叠层复合材料。微观结构观察表明叠 层由反应层和剩余镍层交替组成，且反应层由多个金属间化合物单层构成。这些金属间化合物相的成分呈梯度分布，且随试样处理温度 的升高, 逐步由富铝相向富镍相转变。相应地, 叠层复合材料的抗拉伸强度随着温度升高而逐渐升高, 在 $1473 \mathrm{~K}$ 温度下制备的复合材料 具有最高的抗拉伸强度和伸长率。拉伸试样的断口形貌显示, 在较低处理温度 (1073 和 $1173 \mathrm{~K}$ ) 制备的叠层复合材料, 其断裂是由于金 属间化合物层内的横向裂纹与镍层内的剪切带交互作用所引起的。随着处理温度升高, 试样的断裂由多重裂纹模式向单裂纹模式转变。
\end{abstract} 关键词：复合材料; 金属间化合物; 自蔓延燃烧合成; 拉伸行为

作者简介: 郭亚杰, 男, 1980 年生, 博士, 讲师, 长安大学材料科学与工程学院, 陕西 西安 710064, 电话: 029-82337340, E-mail: yjguo@chd.edu.cn 